\title{
Guidelines on prosthetic heart valve management in infective endocarditis: a narrative review comparing American Heart Association/American College of Cardiology and European Society of Cardiology guidelines
}

\author{
Umberto Maria Satriano ${ }^{1}$, Antonio Nenna ${ }^{1}$, Cristiano Spadaccio ${ }^{2}$, Francesco Pollari ${ }^{3}$, Theodor Fischlein ${ }^{4}$, \\ Massimo Chello ${ }^{1}$, Francesco Nappi ${ }^{5}$ \\ ${ }^{1}$ Cardiovascular surgery, Università Campus Bio-Medico di Roma, Rome, Italy; ${ }^{2}$ Cardiac surgery, Golden Jubilee National Hospital, Glasgow, UK; \\ ${ }^{3}$ Cardiac Surgery, Klinikum Nürnberg, Paracelsus Medical University, Nuremberg, Germany; ${ }^{4}$ Cardiac Surgery, Paracelsus Medical University, \\ Nuremberg, Germany; ${ }^{5}$ Cardiac Surgery, Centre Cardiologique du Nord de Saint-Denis, Paris, France \\ Contributions: (I) Conception and design: C Spadaccio, UM Satriano, M Chello; (II) Administrative support: F Nappi, T Fischlein, M Chello; (III) \\ Provision of study materials or patients: A Nenna, UM Satriano; (IV) Collection and assembly of data: A Nenna, UM Satriano, F Pollari; (V) Data \\ analysis and interpretation: A Nenna, C Spadaccio, UM Satriano; (VI) Manuscript writing: All authors; (VII) Final approval of manuscript: All authors. \\ Correspondence to: Cristiano Spadaccio, MD, PhD. Department of Cardiac Surgery, Golden Jubilee National Hospital, Agamemnon Street Clydebank, \\ Glasgow, G81 4DY, UK. Email: cristianospadaccio@gmail.com.
}

\begin{abstract}
Infective endocarditis (IE) represented over the last year a growing medical and surgical concern. The changes in etiology and demographic of the disease, which now includes also a large proportion of iatrogenic conditions, has prompted new studies and updates in the guideline for IE treatment. The increasing use of intravascular and intracardiac devices has introduced new challenges in terms of both antibiotic resistance and surgical treatment of prosthetic endocarditis. Also, patients with complex congenital heart diseases, intravenous drug abusers and patients with chronic renal failure under hemodialysis have been added to the list of high-risk subjects for IE. Important aspects concerning the establishment of the endocarditis team, the clinical management, the optimal medical therapy and the indication and timing for surgery are arguments of debate and controversy across the literature. In particular, the most adequate strategy to be adopted in the context of concomitant neurological complication remains greatly debated. Despite attempts to standardize the practice in IE, the lack of powered randomized clinical evidence prevented the achievement of a univocal consensus in several aspects of the management of IE. This situation reflects in some differences in the recommendation promoted by the European Society of Cardiology and American Heart Association/American College of Cardiology. In this review, we will compare the European Society of Cardiology and the American Heart Association guidelines and discuss important aspects related to clinical management and indications of for treatment.
\end{abstract}

Keywords: Guidelines; infective endocarditis (IE); clinical management; indications

Submitted Jul 04, 2020. Accepted for publication Aug 14, 2020.

doi: $10.21037 / \mathrm{atm}-20-5134$

View this article at: http://dx.doi.org/10.21037/atm-20-5134

\section{Introduction}

Infective endocarditis (IE) is a condition that mainly affects the heart valves with an incidence between 3 and 10 episodes per 100,000 people/year reaching a peak incidence of almost 14.5 episodes per 100,000 people/years in elderly patients $(1,2)$.

Due to the increase in endovascular procedures, there has been an increase in nosocomial IE although communityacquired IE still prevails as far the general incidence of the 
disease. The increased life-expectancy and aging of the population, the growing incidence of age-related valve disease and the widespread use of implantable electrophysiological devices (CIED) constitute crucial factors in the current IE demographics. Patients with complex congenital heart diseases, intravenous drug abusers (IVDU) and patients with chronic renal failure under hemodialysis are becoming the new high risk subjects for IE (2). The increase in the incidence of bacteremia due to Staphylococcus species has increased the number of cases of acute IE with a faster and more destructive course (3). IVDU remain the most difficult to manage as burdened by worse long-term outcomes in comparison to age-matched population and most likely requiring surgery and prolonged hospitalization $(4,5)$.

Clinical presentation of IE is variegated and includes systemic complication, infective embolization, as well as significant alteration of the physiological cardiac anatomy. Systemic complications with the development of multiorgan dysfunction and sepsis are unfortunately also frequent. It can cause serious complications and is associated with high mortality (1-3).

Early recognition and rapid medical treatment of patients with IE, as well as the identification of the correct timing of the surgical intervention, are strategic moments to optimize the outcome of these patients. It is very important that these patients are rapidly referred to specialized centers and evaluated by multidisciplinary teams of experts in order to be directed as quickly as possible towards the correct therapeutic path.

The establishment and formalization of multidisciplinary endocarditis management teams with approved protocols helped to achieve faster diagnosis and more standardized medical and surgical protocols, improving the survival of patients and decreasing their hospital stay $(6,7)$.

However, despite attempts to standardize the practice in IE, the lack of powered randomized clinical evidence and the changing scenario of this daunting disease prompted over the course of the years new studies and updates of both the European and American Society's guidelines for the management of IE (8).

When analyzing the current guidelines that regulate the treatment of this condition from both European Society of Cardiology (ESC) (9) and the American Heart Association (AHA)/American College of Cardiology (ACC) (3) it is possible to notice some aspects of non-univocal consensus regarding the diagnostics and treatment of the disease. A comparison focusing on the role of imaging in the evaluation and management of IE has been recently published (8).
In this review, we will compare the guidelines and discuss important aspects related to the clinical management and indications of for treatment.

We present the following article in accordance with the Narrative Review reporting checklist (available at http:// dx.doi.org/10.21037/atm-20-5134).

\section{The endocarditis team}

A multidisciplinary approach is recommended and the "endocarditis team" integrates the specific knowledge and expertise of different specialists (cardiologists, anesthesiologists, cardiac surgeons, neurologists, neurosurgeons, infectious disease specialists, microbiologists) (9). Lately, the endocarditis team has acquired an increasing importance to optimize the diagnostic process, decision-making and treatment of the patient.

Implementation of an approach with an "endocarditis team" has shown significant clinical benefits, especially in high-risk patients and patients with heart failure $(10,11)$. Also, the use of this multidisciplinary management framework has shown a significant reduction of 1 -year mortality (from $18.2 \%$ to $8.2 \%$ ) a better compliance to antimicrobial therapy and fewer cases of renal failure in addition to a reduction of deaths due to embolic events or multi-organ failure syndrome (6). Furthermore, a significant reduction in the overall in-hospital $(28 \%$ vs. $13 \%, \mathrm{P}=0.02)$ and 3 -year mortality ( $34 \%$ vs. $16 \%, \mathrm{P} \leq 0.001$ ), as well as a lower mortality for surgery during the active phase $(47 \%$ vs. $13 \%, \mathrm{P} \leq 0.001$ ) was reported (12).

Many professional figures constitute the endocarditis team: cardiologists with echocardiographic expertise, radiologists, microbiologists and infectious disease specialists to identify the adequate antibiotic therapy scheme, cardiac surgeons to define indications and timing for surgery, neurologists in case of neurological complications, surgeons and vascular interventionists to manage other systemic embolic complications (splenic abscesses and peripheral embolism).

Despite patients with isolated, non-high-risk IE could be managed in small, non-specialized centers, regular communication with a multidisciplinary team of endocarditis in the reference centers should be established. Onset of complications or the lack of improvement, should prompt a quick transfer of the patient to referral centers with an endocarditis team. It should also be considered that the role of the endocarditis team is not only limited to the management of patients with IE, but also involves education 
Table 1 Clinical evaluation

\begin{tabular}{|c|c|c|}
\hline Guidelines & Recommendation & Level/class of evidence \\
\hline ESC guidelines & $\begin{array}{l}\text { For patients with uncomplicated IE managed in a non-reference center, early and regular } \\
\text { communication with the reference center and, when needed, visits to the reference center should } \\
\text { be made }\end{array}$ & Ila/B \\
\hline $\begin{array}{l}\text { AHA/ACC } \\
\text { guidelines }\end{array}$ & $\begin{array}{l}\text { Decisions about timing of surgical intervention should be made by a multispecialty Heart Valve } \\
\text { Team of cardiology, cardiothoracic surgery, and infectious disease specialists }\end{array}$ & l/B \\
\hline
\end{tabular}

Both recommend a multi-disciplinary evaluation of the patient (heart team). IE, Infective endocarditis; ESC, European Society of Cardiology; AHA, American Heart Association; ACC, American College of Cardiology; ID, infectious disease; CHD, congenital heart disease.

Table 2 Surgical indications: heart failure

\begin{tabular}{|c|c|c|}
\hline Guidelines & Recommendation & Level/class of evidence \\
\hline \multirow[t]{2}{*}{ AHA/ACC guidelines } & $\begin{array}{l}\text { Early surgery (during initial hospitalization before completion of a full therapeutic course } \\
\text { of antibiotics) is indicated in patients with IE who present with valve dysfunction resulting } \\
\text { in symptoms of HF }\end{array}$ & I/B \\
\hline & $\begin{array}{l}\text { Early surgery (during initial hospitalization before completion of a full therapeutic course } \\
\text { of antibiotics) is indicated in patients with IE complicated by heart block, annular or aortic } \\
\text { abscess, or destructive penetrating lesions }\end{array}$ & I/B \\
\hline
\end{tabular}

ESC guidelines show greater stratification in choosing the correct intervention timing. Both identify the onset of symptoms attributable to $\mathrm{HF}$ and the presence of cardiac structural damage as an indication for surgical treatment. IE, Infective endocarditis; ESC, European Society of Cardiology; AHA, American Heart Association; ACC, American College of Cardiology; HF, heart failure; NVE, native valve endocarditis; PVE, prosthetic valve endocarditis.

of medical students, health care workers and the contribute with clinical research to the improvement of the global care standard (13).

\section{Clinical scenario}

There are many factors that play a fundamental role in the development of the natural history of IE. Cardiac structural anomalies and pre-existing comorbidities, type of infected valve (native or prosthetic), position (aortic, mitral, or right-sided), the type of pathogenic microorganisms and its virulence and the systemic involvement other organs beyond the heart (14-16).
Stapbylococci species (S. aureus being more aggressive and destructive) and streptococci are the most common, aggressive and destructive bacteria. The extent of the infection relates to microorganism virulence and duration of the infection (1). Early diagnosis of the disease and prevention of the development of local and systemic complications are essential in order to optimize the patient's outcomes (17). Importantly, the timing and indication for invasive treatment also constitutes a fundamental part of the decision-making process.

It is sobering to note that one of the aspects of nonuniformity among the currently available guidelines for IE relies in the definition of criteria and timing for surgery. 
Table 3 Surgical indications: uncontrolled infection

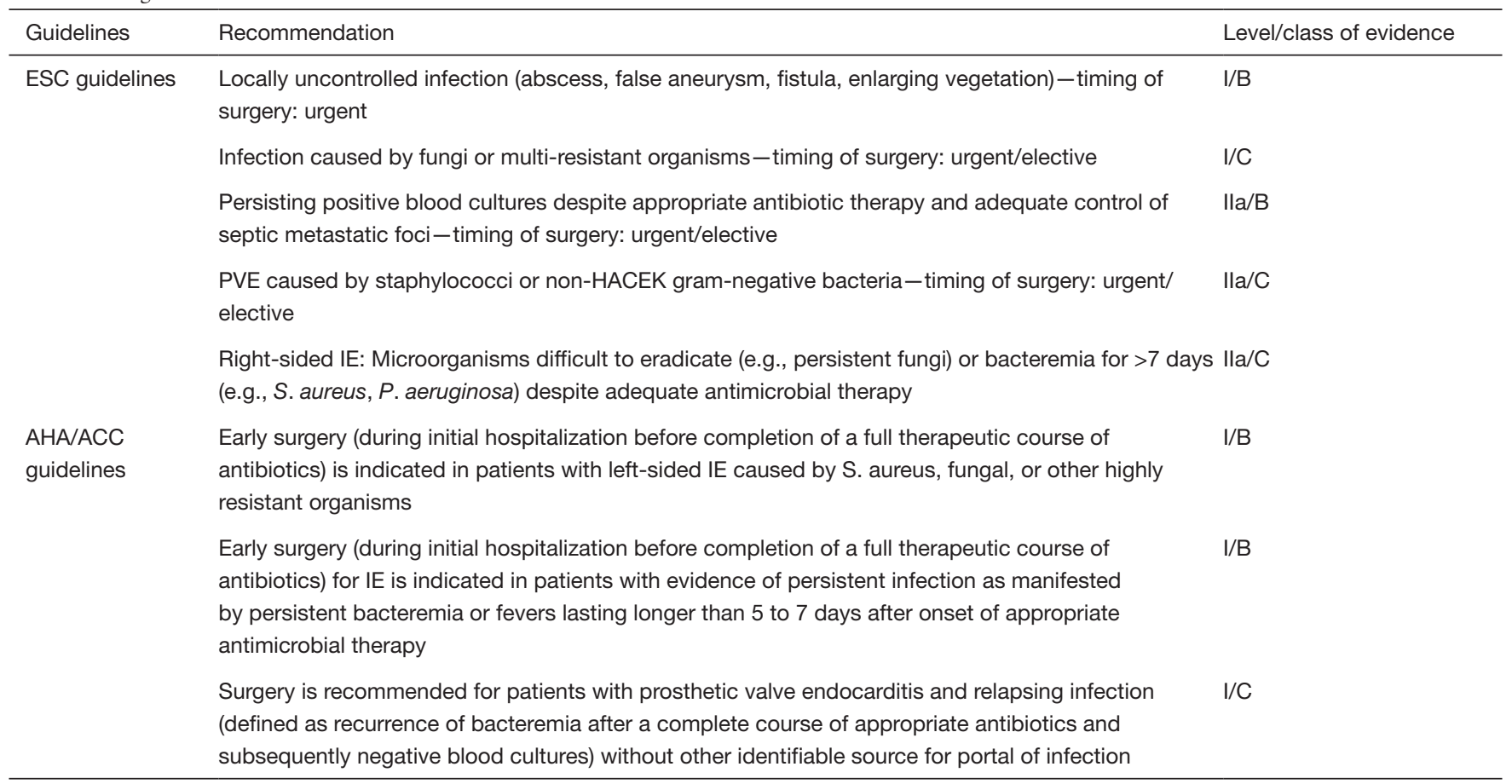

ESC guidelines show greater stratification in choosing the correct intervention timing. The AHA/ACC guidelines show greater attention to the onset of symptoms and contemplate a specific indication for IE arisen on a prosthetic valve. Both identify infections refractory to antibiotic therapy or infections caused by microorganisms that are difficult to eradicate as an indication for surgery. IE, Infective endocarditis; ESC, European Society of Cardiology; AHA, American Heart Association; ACC, American College of Cardiology.

Table 4 Surgical indications: prevention of embolism

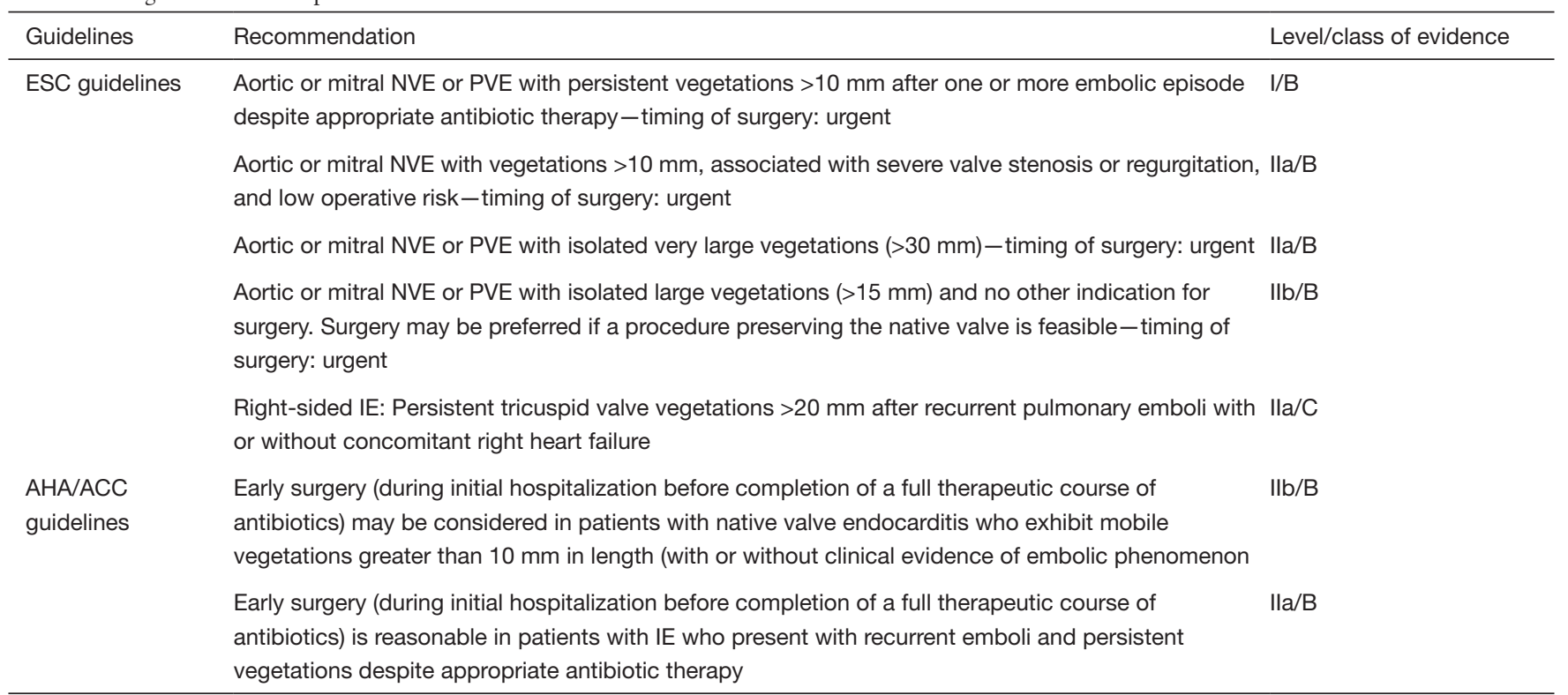

ESC guidelines show greater stratification in choosing the correct intervention timing, in assessing the size of the vegetation and the functioning of the valve on which it is positioned. The ESC guidelines also highlight a different indication in relation to the occurrence of embolic events. The AHA ACC guidelines give greater importance to the possibility of reducing the size of vegetation with antibiotic therapy. IE, Infective endocarditis; ESC, European Society of Cardiology; AHA, American Heart Association; ACC, American College of Cardiology; NVE, native valve endocarditis; PVE, prosthetic valve endocarditis. 
Table 5 Management of neurologic complications of infective endocarditis

\begin{tabular}{|c|c|c|}
\hline Guidelines & Recommendation & Level/class of evidence \\
\hline \multirow{2}{*}{ ESC guidelines } & Following intracranial haemorrhage, surgery should generally be postponed for $\geq 1$ month & $\mathrm{Ila} / \mathrm{B}$ \\
\hline & $\begin{array}{l}\text { After a stroke, surgery indicated for HF, uncontrolled infection, abscess, or persistent high } \\
\text { embolic risk should be considered without any delay as long as coma is absent and the } \\
\text { presence of cerebral haemorrhage has been excluded by cranial CT or MRI }\end{array}$ & Ila/B \\
\hline \multirow[t]{2}{*}{ AHA/ACC guidelines } & $\begin{array}{l}\text { Operation without delay may be considered in patients with IE and an indication for } \\
\text { surgery who have suffered a stroke but have no evidence of intracranial hemorrhage or } \\
\text { extensive neurological damage }\end{array}$ & $\mathrm{Ilb} / \mathrm{C}$ \\
\hline & $\begin{array}{l}\text { Delaying valve surgery for at least } 4 \text { weeks may be considered for patients with IE and } \\
\text { major ischemic stroke or intracranial hemorrhage if the patient is hemodynamically stable }\end{array}$ & $\mathrm{Ilb} / \mathrm{C}$ \\
\hline
\end{tabular}

In both guidelines, the present of cerebral hemorrhage forces to postpone the surgery and the patient's clinical conditions (both neurological and hemodynamic) play a fundamental role in confirming the indication. The ESC guidelines show more attention to the colonization of other organs by pathogenic organisms. IE, Infective endocarditis; ESC, European Society of Cardiology; AHA, American Heart Association; ACC, American College of Cardiology; HF, heart failure.

Table 6 Cardiac device-related IE

\begin{tabular}{|c|c|c|}
\hline Guidelines & Recommendation & Level/class of evidence \\
\hline ESC guidelines & $\begin{array}{l}\text { Complete hardware removal should be considered on the basis of occult infection without } \\
\text { another apparent source of infection }\end{array}$ & $\mathrm{Ila} / \mathrm{C}$ \\
\hline \multirow[t]{2}{*}{$\begin{array}{l}\text { AHA/ACC } \\
\text { guidelines }\end{array}$} & $\begin{array}{l}\text { Complete removal of pacemaker or defibrillator systems, including all leads and the generator, } \\
\text { is indicated as part of the early management plan in patients with IE with documented infection } \\
\text { of the device or lead }\end{array}$ & I/B \\
\hline & $\begin{array}{l}\text { Complete removal of pacemaker or defibrillator systems, including all leads and the generator, } \\
\text { is reasonable in patients with valvular IE caused by } S \text {. aureus or fungi, even without evidence } \\
\text { of device or lead infection }\end{array}$ & Ila/B \\
\hline
\end{tabular}

Both guidelines recommend the removal and replacement of intra and extra cardiac devices, even if not located in the primitive site of the infection. The AHA/ACC guidelines pay more attention to the microorganism responsible for the infection. IE, Infective endocarditis; ESC, European Society of Cardiology; AHA, American Heart Association; ACC, American College of Cardiology; CDRIE, cardiac device related infective endocarditis; NVE, native valve endocarditis; PVE, prosthetic valve endocarditis.

\section{Comparison of the ESC and AHA/ACC guidelines}

Current guidelines were compared in terms of clinical evaluation (Table 1), surgical indications (Table 2 for heart failure, Table 3 for uncontrolled infection, Table 4 for prevention of embolism), management of neurologic complications (Table 5) and cardiac device-related IE (Table 6).

\section{Discussion}

\section{Surgery for IE}

IE treatment is based on a combination of medical therapy with antibiotics and surgery. The latter is necessary in some specific conditions identified by the guidelines. As shown 
in Tables 1-4, the ESC and ACC/AHA guidelines agree on multiple aspects. Antibiotic therapy, although necessary, is often ineffective in controlling extensive infections affecting large areas of myocardial or prosthetic tissue (large vegetations, abscesses, fistulas). In these cases, delaying surgery could adversely affect patient outcome by increasing the risk of developing local and systemic complications (18), destruction of valvular tissue and invasion of paravalvular structures (19). The micro-organism identified as responsible for the infection represents a possible surgical indication per se. The isolation of very aggressive and antibiotic-resistant micro-organisms as S. aureus (20) or some fungi are direct indications for surgery (1).

Presence of cerebral embolism is not a contraindication for early surgery, but in case of cerebral hemorrhage it is recommended to delay the surgery by four weeks. In these cases, consultation with neurologists or neurosurgeons is fundamental.

\section{Surgical timing}

The goal of the endocarditis team should be to prevent the development of complications. In this context, decisionmaking on the timing for intervention is crucial to prevent embolic complications. Surgery should be performed at early stages in patients with large vegetations or intracardiac prosthetic material, where the risk of embolization or development of perivalvular abscesses is high $(18,19)$. Delaying surgery in hemodynamically stable patients with adequate antimicrobial therapy but with established indication for surgery is not associated with further benefits or is even detrimental according to a number of observational studies (21-25).

The decision of the correct therapeutic strategy to be applied in patients with IE and neurological complications is a very challenging. The lines ESC and ACC/AHA provide substantially univocal indications although they present some differences (Table 5). There are many neurological complications that can be observed during IE: ischemic stroke, cerebral hemorrhage (ICH), cerebral microbleeds, intracranial infectious aneurysms, and remote dissemination of infectious foci.

In ischemic stroke, the guidelines seem to suggest early surgery. However, while on the one hand the removal of the embolic source would protect the patient from future embolic events, on the other hand there it has been reported an increase in the onset of further neurological complications in patients undergoing early surgery $(26,27)$.
An analysis of the available literature provides contradictive findings. While some studies suggest that delayed surgery in stroke patients would correspond to an improvement in the clinical outcomes $(28,29)$, more recent report and metaanalysis of observational studies contest these hypotheses and showed that early surgery is non-inferior to delayed surgery for major stroke patients and would even improve outcomes in minor stroke patients $(30,31)$.

In case of $\mathrm{ICH}$, the guidelines suggest waiting at least 3-4 weeks before surgery. This indication is supported by studies showing rapid deterioration of neurological conditions in patients undergoing early surgery (31-34). On the other hand, recent studies have re-discussed this topic showing how the risk of disease progression in patients with ICH is very low, giving early surgery a greater safety profile $(35,36)$. In support of this thesis, Salaun et al. in recent single center study have shown that patients who present with ICH show a higher mortality if treated conservatively when IE surgery is indicated (37). Other studies have shown not only non-inferiority of surgery performed within 2 weeks of the bleeding event, but also an improvement in the outcomes in terms of mortality $(31,35,38)$. Parameters as the size of the hemorrhagic area and the presence of hemorrhagic infarction of brain tissue have become increasingly important in the stratification of patients presenting with $\mathrm{ICH}$ (39).

Surely, these controversies warrant the need for further studies deepening knowledge on this argument.

\section{Gaps in knowledge}

Despite several aspects of IE management are challenging and debated, the most important gaps in knowledge relate to the correct timing of surgery in patients with neurological complications, the role of early surgery to prevent embolism, and in patient with prosthetic valve endocarditis (PVE). These areas require further evidences to formulate a correct decisional algorithm.

\section{Conclusions}

The presence discrepancies between different guidelines is an indicator of the difficulty in the identification of the correct therapeutic strategy of patients with IE, especially in those burdened by neurological complications.

The difficulty in performing randomized trials in this field has conspired against the agreement on univocal indications on IE management and left the evidences on 
some particular aspects to the level of "expert opinion". Despite a general adherence to the guidelines, the clinical practice is often multifaceted and inevitably influenced by surgeons' experience or predilection.

The possibility of postponing surgery for 4 weeks after a cerebral hemorrhage protects patients from an increased risk of bleeding during cardiopulmonary by-pass. On the other hand, septic embolization of endocarditic vegetation is the most frequent cause of stroke with hemorrhagic degeneration. Delaying the surgery means exposing the patient to the risk of new embolic events with negative impact on clinical outcomes.

Currently, the literature does not provide sufficient information to provide an unambiguous answer to these questions. Elements of the clinical history, comorbidity, extent of the infection, presence of intra-cardiac prosthetic materials could guide decision-making in the context of the endocarditis team. However, only further investigations with specific aims could shed light on these challenging interrogatives.

\section{Acknowledgments}

Funding: None.

\section{Footnote}

Provenance and Peer Review: This article was commissioned by the Guest Editors (Drs. Francesco Nappi, Christos Mihos, and Cristiano Spadaccio) for the series "Infective Endocarditis in the 21st Century" published in Annals of Translational Medicine. The article was sent for external peer review organized by the Guest Editors and the editorial office.

Reporting Checklist: The authors have completed the Narrative Review reporting checklist. Available at http:// dx.doi.org/10.21037/atm-20-5134

Conflicts of Interest: The authors have completed the ICMJE uniform disclosure form (available at http:// dx.doi.org/10.21037/atm-20-5134). The series "Infective Endocarditis in the 21st Century" was commissioned by the editorial office without any funding or sponsorship. FN served as the unpaid Guest Editor of the series and serves as an unpaid editorial board member of Annals of Translational Medicine from Feb 2019 to Jan 2021. CS served as the unpaid Guest Editor of the series. The authors have no other conflicts of interest to declare.

Ethical Statement: The authors are accountable for all aspects of the work in ensuring that questions related to the accuracy or integrity of any part of the work are appropriately investigated and resolved.

Open Access Statement: This is an Open Access article distributed in accordance with the Creative Commons Attribution-NonCommercial-NoDerivs 4.0 International License (CC BY-NC-ND 4.0), which permits the noncommercial replication and distribution of the article with the strict proviso that no changes or edits are made and the original work is properly cited (including links to both the formal publication through the relevant DOI and the license). See: https://creativecommons.org/licenses/by-nc-nd/4.0/.

\section{References}

1. Wang A, Gaca JG, Chu VH. Management Considerations in Infective Endocarditis: A Review. JAMA 2018;320:72-83.

2. Gibbons EF, Huang G, Aldea G, et al. A Multidisciplinary Pathway for the Diagnosis and Treatment of Infectious Endocarditis. Crit Pathw Cardiol 2020;19:187-94.

3. Baddour LM, Wilson WR, Bayer AS, et al. Infective Endocarditis in Adults: Diagnosis, Antimicrobial Therapy, and Management of Complications: A Scientific Statement for Healthcare Professionals From the American Heart Association. Circulation 2015;132:1435-86.

4. Shrestha NK, Jue J, Hussain ST. Injection drug use and outcomes after surgical intervention for infective endocarditis. Ann Thorac Surg 2015;100:875-82.

5. Rudasill SE, Sanaiha Y, Mardock AL, et al. Clinical Outcomes of Infective Endocarditis in Injection Drug Users. J Am Coll Cardiol 2019;73:559-70.

6. Botelho-Nevers E, Thuny F, Casalta JP, et al. Dramatic reduction in infective endocarditis-related mortality with a management-based approach. Arch Intern Med 2009;169:1290-8.

7. Mestres CA, Paré JC, Miró JM, et al. Organization and Functioning of a Multidisciplinary Team for the Diagnosis and Treatment of Infective Endocarditis: A 30year Perspective (1985-2014). Rev Esp Cardiol (Engl Ed) 2015;68:363-8.

8. Murphy DJ, Din M, Hage FG, et al. Guidelines in review: Comparison of ESC and AHA guidance for the diagnosis and management of infective endocarditis in adults. J Nucl Cardiol 2019;26:303-8. 
9. Habib G, Lancellotti P, Antunes MJ, et al. 2015 ESC Guidelines for the management of infective endocarditis: The Task Force for the Management of Infective Endocarditis of the European Society of Cardiology (ESC). Endorsed by: European Association for Cardio-Thoracic Surgery (EACTS), the European Association of Nuclear Medicine (EANM). Eur Heart J 2015;36:3075-128.

10. Lancellotti P, Rosenhek R, Pibarot P, et al. ESC Working Group on Valvular Heart Disease position paper--heart valve clinics: organization, structure, and experiences. Eur Heart J 2013;34:1597-606.

11. Ponikowski P, Voors AA, Anker SD, et al. 2016 ESC Guidelines for the diagnosis and treatment of acute and chronic heart failure: The Task Force for the diagnosis and treatment of acute and chronic heart failure of the European Society of Cardiology (ESC). Developed with the special contribution of the Heart Failure Association (HFA) of the ESC. Eur J Heart Fail 2016;18:891-975.

12. Chirillo F, Scotton P, Rocco F, et al. Impact of a multidisciplinary management strategy on the outcome of patients with native valve infective endocarditis. Am J Cardiol 2013;112:1171-6.

13. Davierwala PM, Marin-Cuartas M, Misfeld M, et al. The value of an "Endocarditis Team." Ann Cardiothorac Surg 2019;8:621-9.

14. Hussain ST, Shrestha NK, Gordon SM, et al. Residual patient, anatomic, and surgical obstacles in treating active left-sided infective endocarditis. J Thorac Cardiovasc Surg 2014;148:981-8.e4.

15. Manne MB, Shrestha NK, Lytle BW, et al. Outcomes after surgical treatment of native and prosthetic valve infective endocarditis. Ann Thorac Surg 2012;93:489-93.

16. Pettersson GB, Hussain ST, Shrestha NK. Infective endocarditis: an atlas of disease progression for describing, staging, coding, and understanding the pathology. J Thorac Cardiovasc Surg 2014;147:1142-9.

17. Pettersson GB, Hussain ST. Current AATS guidelines on surgical treatment of infective endocarditis. Ann Cardiothorac Surg 2019;8:630-44.

18. Hubert S, Thuny F, Resseguier N, et al. Prediction of symptomatic embolism in infective endocarditis: construction and validation of a risk calculator in a multicenter cohort. J Am Coll Cardiol 2013;62:1384-92.

19. Rizzi M, Ravasio V, Carobbio A, et al. Predicting the occurrence of embolic events: an analysis of 1456 episodes of infective endocarditis from the Italian Study on Endocarditis (SEI). BMC Infect Dis 2014;14:230.

20. Fowler VG, Miro JM, Hoen B, et al. Staphylococcus aureus endocarditis: a consequence of medical progress. JAMA 2005;293:3012-21.

21. Gálvez-Acebal J, Almendro-Delia M, Ruiz J, et al. Influence of early surgical treatment on the prognosis of left-sided infective endocarditis: a multicenter cohort study. Mayo Clin Proc 2014;89:1397-405.

22. Aksoy O, Sexton DJ, Wang A. Early Surgery in Patients with Infective Endocarditis: A Propensity Score Analysis. Clin Infect Dis 2007;44:364-72.

23. Mirabel M, Sonneville R, Hajage D, et al. Long-term outcomes and cardiac surgery in critically ill patients with infective endocarditis. Eur Heart J 2014;35:1195-204.

24. Samura T, Yoshioka D, Toda K, et al. Emergency valve surgery improves clinical results in patients with infective endocarditis complicated with acute cerebral infarction: analysis using propensity score matching $\dagger$. Eur J Cardiothorac Surg 2019;56:942-9.

25. Wang A, Pappas P, Anstrom KJ, et al. The use and effect of surgical therapy for prosthetic valve infective endocarditis: a propensity analysis of a multicenter, inter-national cohort. Am Heart J 2005;150:1086-91.

26. Angstwurm K, Borges AC, Halle E, et al. Timing the valve replacement in infective endocarditis involving the brain. J Neurol 2004;251:1220-6.

27. Maruyama M, Kuriyama Y, Sawada T, et al. Brain damage after open heart surgery in patients with acute cardioembolic stroke. Stroke 1989;20:1305-10.

28. Barsic B, Dickerman S, Krajinovic V, et al. Influence of the timing of cardiac surgery on the outcome of patients with infective endocarditis and stroke. Clin Infect Dis 2013;56:209-17.

29. Morita K, Sasabuchi Y, Matsui H, et al. Outcomes after early or late timing of surgery for infective endocarditis with ischaemic stroke: a retrospective cohort study. Interact Cardiovasc Thorac Surg 2015;21:604-9.

30. Murai R, Funakoshi S, Kaji S, et al. Outcomes of early surgery for infective endocarditis with moderate cerebral complications. J Thorac Cardiovasc Surg 2017;153:831-40.e8.

31. Tam DY, Yanagawa B, Verma S, et al. Early vs Late Surgery for Patients With Endocarditis and Neurological Injury: A Systematic Review and Meta-analysis. Can J Cardiol 2018;34:1185-99.

32. Ruttmann E, Willeit J, Ulmer H, et al. Neurological outcome of septic cardioembolic stroke after infective endocarditis. Stroke 2006;37:2094-9.

33. García-Cabrera E, Fernández-Hidalgo N, Almirante B, et al. Neurological complications of infective endocarditis: risk factors, outcome, and impact of cardiac 
surgery: a multicenter observational study. Circulation 2013;127:2272-84.

34. Eishi K, Kawazoe K, Kuriyama Y, et al. Surgical management of infective endocarditis associated with cerebral complications. Multicenter retrospective study in Japan. J Thorac Cardiovasc Surg 1995;110:1745-55.

35. Yoshioka D, Toda K, Sakaguchi T, et al. Valve surgery in active endocarditis patients complicated by intracranial haemorrhage: the influence of the timing of surgery on neurological outcomes. Eur J Cardiothorac Surg 2014;45:1082-8.

36. Venn RA, Ning M, Vlahakes GJ, et al. Surgical timing in infective endocarditis complicated by intracranial

Cite this article as: Satriano UM, Nenna A, Spadaccio C, Pollari F, Fischlein T, Chello M, Nappi F. Guidelines on prosthetic heart valve management in infective endocarditis: a narrative review comparing American Heart Association/ American College of Cardiology and European Society of Cardiology guidelines. Ann Transl Med 2020;8(23):1625. doi: 10.21037/atm-20-5134 hemorrhage. Am Heart J 2019;216:102-12.

37. Salaun E, Touil A, Hubert S, et al. Intracranial haemorrhage in infective endocarditis. Arch Cardiovasc Dis 2018;111:712-21.

38. Kume Y, Fujita T, Fukushima S, et al. Intracranial mycotic aneurysm is associated with cerebral bleeding post-valve surgery for infective endocarditis. Interact Cardiovasc Thorac Surg 2018;27:635-41.

39. Carneiro TS, Awtry E, Dobrilovic N, et al. Neurological Complications of Endocarditis: A Multidisciplinary Review with Focus on Surgical Decision Making. Semin Neurol 2019;39:495-506. 